\title{
Simulating the temperature and precipitation signal in an Alpine ice core
}

\author{
S. Brönnimann ${ }^{1,2}$, I. Mariani ${ }^{1,3}$, M. Schwikowski ${ }^{1,3}$, R. Auchmann ${ }^{1,2}$, and A. Eichler ${ }^{1,3}$ \\ ${ }^{1}$ Oeschger Centre, University of Bern, Switzerland \\ ${ }^{2}$ Institute of Geography, University of Bern, Switzerland \\ ${ }^{3}$ Paul Scherrer Institute, Villigen, Switzerland
}

Correspondence to: S. Brönnimann (stefan.broennimann@giub.unibe.ch)

Received: 20 November 2012 - Published in Clim. Past Discuss.: 10 December 2012

Revised: 12 June 2013 - Accepted: 15 July 2013 - Published: 22 August 2013

\begin{abstract}
Accumulation and $\delta^{18} \mathrm{O}$ data from Alpine ice cores provide information on past temperature and precipitation. However, their correlation with seasonal or annual mean temperature and precipitation at nearby sites is often low. This is partly due to the irregular sampling of the atmosphere by the ice core (i.e. ice cores almost only record precipitation events and not dry periods) and the possible incongruity between annual layers and calendar years. Using daily meteorological data from a nearby station and reanalyses, we replicate the ice core from the Grenzgletscher (Switzerland, $4200 \mathrm{~m}$ a.s.l.) on a sample-by-sample basis by calculating precipitation-weighted temperature (PWT) over short intervals. Over the last $15 \mathrm{yr}$ of the ice core record, accumulation and $\delta^{18} \mathrm{O}$ variations can be well reproduced on a sub-seasonal scale. This allows a wiggle-matching approach for defining quasi-annual layers, resulting in high correlations between measured quasi-annual $\delta^{18} \mathrm{O}$ and PWT. Further back in time, the agreement deteriorates. Nevertheless, we find significant correlations over the entire length of the record (1938-1993) of ice core $\delta^{18} \mathrm{O}$ with PWT, but not with annual mean temperature. This is due to the low correlations between PWT and annual mean temperature, a characteristic which in ERA-Interim reanalysis is also found for many other continental mid-to-high-latitude regions. The fact that meteorologically very different years can lead to similar combinations of PWT and accumulation poses limitations to the use of $\delta^{18} \mathrm{O}$ from Alpine ice cores for temperature reconstructions. Rather than for reconstructing annual mean temperature, $\delta^{18} \mathrm{O}$ from Alpine ice cores should be used to reconstruct PWT over quasi-annual periods. This variable is reproducible in reanalysis or climate model data and could thus be assimilated into conventional climate models.
\end{abstract}

\section{Introduction}

Alpine ice cores have been used as climate proxies to infer environmental conditions in the past, including temperature and precipitation. Precipitation is reflected in the net accumulation rate, and temperature in the $\delta^{18} \mathrm{O}$ isotopic composition. However, the direct calibration of these proxy variables with observed seasonal or annual mean temperature and precipitation is difficult and correlations are sometimes low. For instance, for the case of the Grenzgletscher in Switzerland (4200 m a.s.l., see Fig. 1), a high-accumulation site with presumably good data quality (Eichler et al., 2000, 2001), the correlation between $\delta^{18} \mathrm{O}$ in the ice core and annual mean temperature from nearby meteorological stations is low, while there is a significant correlation between accumulation and precipitation (see Mariani et al., 2012, for a more detailed discussion of the Grenzgletscher ice core and correlations with meteorological fields).

There are many possible causes why $\delta^{18} \mathrm{O}$ and accumulation might not correlate well with nearby annual mean meteorological records (see also Sturm et al., 2010, for a review). For instance, precipitation may exhibit a very local signal that is not captured by nearby sites, particularly in the complex Alpine setting. Even if local precipitation was available, local accumulation does not record local precipitation, as there may be a substantial redistribution of snow (wind drift, erosion). Also, $\delta^{18} \mathrm{O}$ does not record local air temperature but depends on the origin and history of the water vapour in the air mass including possibly multiple condensation cycles (e.g. Pfahl and Wernli, 2008). Isotopic composition is known to change with the amount of precipitation due to 
changes in sub-cloud humidity and drop size (Lee and Fung, 2008).

Postdepositional processes (e.g. diffusion, surface melting, lateral percolation, sublimation) lead to a smoothing and dislocation of the signal within the ice core (Eichler et al., 2001) or to changes in the isotopic signature (Steen-Larsen et al., 2012). Ice flow may change the structure of the record. The snow sampled in deeper layers of the ice core might have fallen further up on the glacier under different conditions (upstream effects). Finally, ice cores record climatic conditions almost only during precipitation events, which may not be characteristic for the average conditions over a year or so.

The $\delta^{18} \mathrm{O}$ signal thus represents a precipitation-weighted temperature signal, not an averaged temperature signal (Werner et al., 2000; Läpple et al., 2011). This problem has been well studied for polar ice cores (Sime et al., 2009, 2011). For instance, Persson et al. (2011) developed a simple model based on ERA-40 reanalysis data and found that the low correlation between isotope values and temperature in northwestern Greenland is due to a lower mean fraction of precipitation during winter and a larger year-to-year variability of this fraction. Casado et al. (2013), also using reanalysis data, addressed temperature biases caused by the difference of precipitation-weighted temperature and seasonal mean temperature and their effects on reconstructions of the North Atlantic Oscillation.

The direct comparison (e.g. correlation, regression) of accumulation or $\delta^{18} \mathrm{O}$ in ice cores with precipitation and seasonal or annual mean temperature can only be successful if the effects of the above-mentioned processes are constant, depend linearly on the measurands (accumulation or $\delta^{18} \mathrm{O}$ ), or compensate each other. However, this assumption may be problematic, specifically in the climatically complex environment of the Alps or mountain systems in general. For instance, a seasonal shift in precipitation from winter to summer between the medieval period and the Little Ice Age might produce lower $\delta^{18} \mathrm{O}$ values in medieval times than during the Little Ice Age, even if temperatures were higher in both seasons (see also Wagenbach et al., 2012, for a thorough discussion of seasonality effects).

In this paper we consider one of the problems mentioned, namely that of the irregular sampling of weather events by the ice core. We address this by replicating the sampling in daily meteorological data using a very simple forward model. We further study the problem of the definition of annual layers in comparisons between meteorological data and proxies. Finally, weather generators are used to further explore the relation between precipitation-weighted temperature (PWT) and annual mean temperature.

The paper is organised as follows. Section 2 gives details about the ice core and meteorological data used in this paper. Section 3 describes the forward modelling approach. Results are presented and discussed in Sect. 4, including analyses with the weather generators. Conclusions are drawn in Sect. 5.

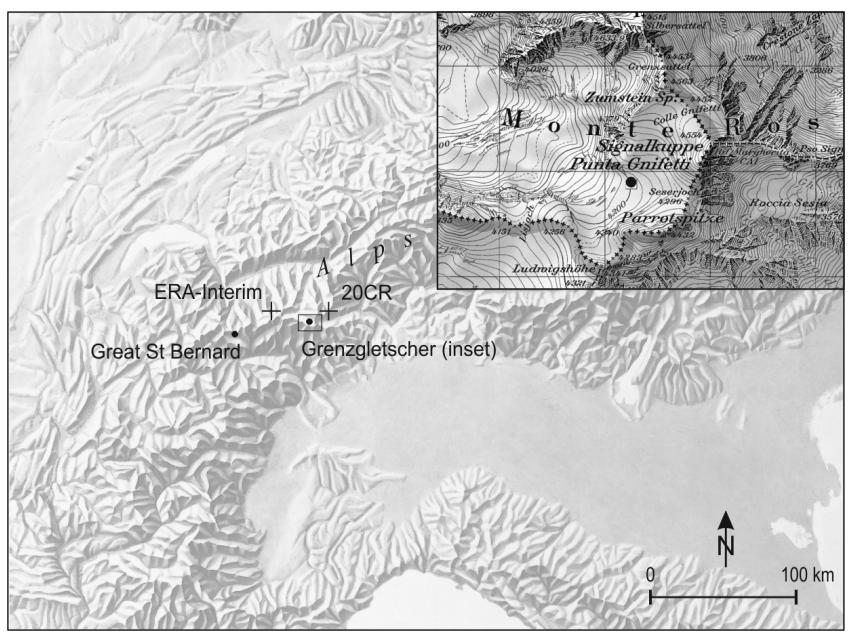

Fig. 1. Map of the study site and the locations of Grenzgletscher and Great St Bernard. The inset shows the drilling location of the Grenzgletscher ice core. Crosses show the locations of the grid points from Twentieth Century Reanalysis (20CR) and ERAInterim. Printed with permission of the Schweizerische Konferenz der Kantonalen Erziehungsdirektoren (relief) and swisstopo (inset).

\section{Data and methods}

\subsection{Ice core data}

We use data from an ice core drilled at the upper Grenzgletscher $\left(45^{\circ} 55^{\prime} \mathrm{N}, 7^{\circ} 52^{\prime} \mathrm{E}\right)$, at an elevation of $4200 \mathrm{~m}$ a.s.l. (see Fig. 1). The Grenzgletscher is situated in the Monte Rosa Massif and is a high-accumulation site. The core studied here was collected in October 1994 and reached a depth of $125 \mathrm{~m}$ (Eichler et al., 2000, 2001). The time period covered by the ice core is 1937-1994, with a mean annual accumulation rate of $2.7 \mathrm{~m}$ water equivalent (w.e.). The density of each ice core section of about $50 \mathrm{~cm}$ length was used to calculate the w.e. depth in order to correct for compaction of the firn part of the core. Sampling resolution was $5 \mathrm{~cm}$ for analyses of $\delta^{18} \mathrm{O}$, corresponding to about 70 and 20 measurements per year for the periods 1984-1993 and 1938-1947, respectively. Between 1953 and 1987, only every other sample was analysed with respect to $\delta^{18} \mathrm{O}$. The core indicated perturbations in the period 1985-1989, strongly affecting the chemical composition but leaving the $\delta^{18} \mathrm{O}$ mostly undisturbed. Eichler et al. (2001) concluded that these perturbations were most likely due to lateral percolation of melt water.

In addition to $\delta^{18} \mathrm{O}$, concentrations of major ions were also determined. Although they are not directly analysed in this paper, they were sometimes used for supporting the identification of seasons. In general, annual layers were then defined as layers between the coldest (lowest) $\delta^{18} \mathrm{O}$ sample of a winter season and the coldest $\delta^{18} \mathrm{O}$ sample of the next year's winter season (referred to as "cold point year" in the following). Annual accumulation rates were calculated from the obtained 
annual thicknesses accounting for thinning of annual layers with depth by using a simple ice flow model (Nye, 1963); for details see Eichler et al. (2000).

\subsection{Meteorological data}

Local meteorological data are used from three main sources: station data, ERA-Interim reanalysis (Dee et al., 2011), and the Twentieth Century Reanalysis (Compo et al., 2011).

The station data are from the Great St Bernard, ca. $50 \mathrm{~km}$ to the west of the ice core site, at an altitude of $2450 \mathrm{~m}$ a.s.l. (see Fig. 1). The station is at a saddle (a pass) on the main Alpine crest and thus influenced both from the north and the south. The station was erected in 1817; sub-daily data reach back to 1819 . However, the data have not yet been fully homogenised. A visual inspection revealed a large, likely unrealistic trend in precipitation up to the 1930s. For the period after 1938, when ice core data are available, no clear inhomogeneity was detected. However, precipitation at Great St Bernard is measured near a south-facing wall, which is expected to affect the measurements due to shielding effects.

As an alternative to the station data, we further included reanalysis data. On the one hand we used ERA-Interim data from 1979 to the present (Dee et al., 2011). This data set represents the latest generation of reanalyses. On the other hand, for going back further, we also used the ensemble mean of the Twentieth Century Reanalysis, version 2 (20CR, Compo et al., 2011), which goes back to 1871. 20CR is a global 3-dimensional atmospheric reanalysis data set at 6hourly temporal resolution reaching back to 1871 (Compo et al., 2011). It provides a 56-member ensemble of analyses based on an assimilation of surface and sea level pressure observations (i.e. the distribution of atmospheric mass). Assimilation was performed using an Ensemble Kalman Filter technique, with first guess fields generated by a 2008 experimental version of the US National Center for Environmental Prediction Global Forecast System (NCEP/GFS) atmosphere/land model. Model boundary conditions were derived from monthly mean sea surface temperature and sea ice distributions (see Compo et al., 2011, for details).

We extracted meteorological data from the closest grid point (with a spatial resolution of $1.5^{\circ} \times 1.5^{\circ}$ and $2^{\circ} \times 2^{\circ}$ for ERA-Interim and 20CR, respectively) to the Grenzgletscher (see Fig. 1). The time interval of the atmospheric data was $6 \mathrm{~h}$ while precipitation in both data sets was available at steps of $3 \mathrm{~h}$ from 12 -hourly forecasts.

We compared the three data sets on the level of daily averages (precipitation was summed from 06:00 UTC to 06:00 UTC). From the reanalysis data sets we used temperature at $600 \mathrm{hPa}$ (which is close to the altitude of Grenzgletscher). For the remainder of the paper, only analyses based on these daily data are shown. Comparisons were performed on absolute values (i.e. no mean annual cycle was subtracted), for the years 1980-2008. The agreement for temperature is very good between all data sets, with Pearson
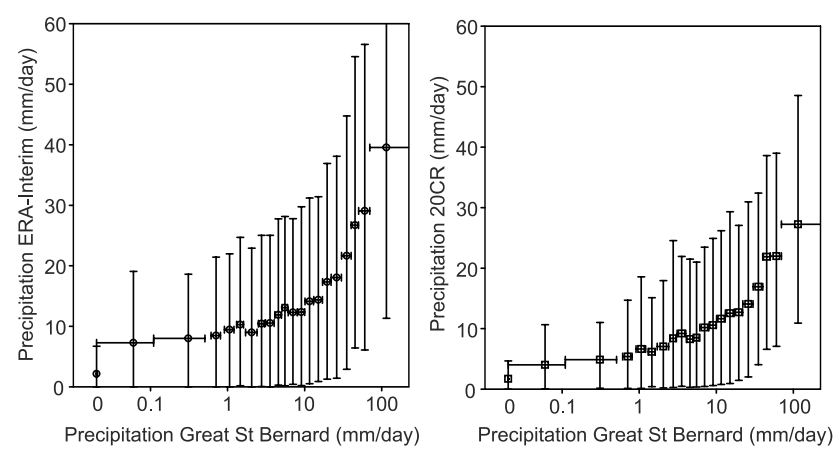

Fig. 2. Comparison of daily precipitation in observations from the Great St Bernard and from ERA-Interim (left) and 20CR (right) reanalysis data in the period 1980-2008. Observed precipitation was binned (horizontal error bars indicate the bin size). The $y$ axes give the average precipitation for each bin (error bars give the 10th and 90th percentiles).

correlations exceeding 0.95. For precipitation (Fig. 2), both reanalysis data sets, but particularly $20 \mathrm{CR}$ (ensemble mean), overestimate the number of precipitation days (conventionally defined as days with $\geq 0.1 \mathrm{~mm}$ of precipitation). In these $29 \mathrm{yr}, 5869$ days were reported, while the numbers for ERAInterim and $20 \mathrm{CR}$ are 7501 and 8578 , respectively. The total precipitation amounts agree relatively well, i.e. they are within $30 \%$ of each other, and interannual variability (see Fig. 3) is in good mutual agreement. However, both reanalyses (especially ERA-Interim) show higher precipitation amounts in summer as compared to observations (Fig. 3).

Correlations for precipitation are relatively low when considering individual days. However, after binning observed precipitation into 21 classes and analysing reanalysis precipitation for each class, the agreement improves (Fig. 2; note the logarithmic scale used for the $x$ axis for display purposes). Pearson correlations of 0.96 and 0.92 are found between class mean values from observations and ERA-Interim or from observations and 20CR, respectively. The relation is non-linear as high values are underestimated. This is expected since observations are point values whereas reanalyses represent precipitation over large areas (also, 20CR is an ensemble mean of 56 members, additionally contributing to an underestimation of extremes and an overestimation of precipitation days). Note also that orography is very crudely depicted in 20CR and hence orographic effects are missing (see Stucki et al., 2012, for a discussion of the accuracy of Alpine precipitation in 20CR and of processes leading to heavy precipitation in the Alps, including orography).

Another way of looking at precipitation agreement between two data sets is to calculate the fraction of total precipitation in one data set that falls on days on which the other also indicates precipitation in excess of $0.1 \mathrm{~mm}$. The numbers for all six mutual comparisons are at least $85 \%$. In all, the agreement for precipitation is satisfactory but not excellent. We use all three data sets in this paper. 

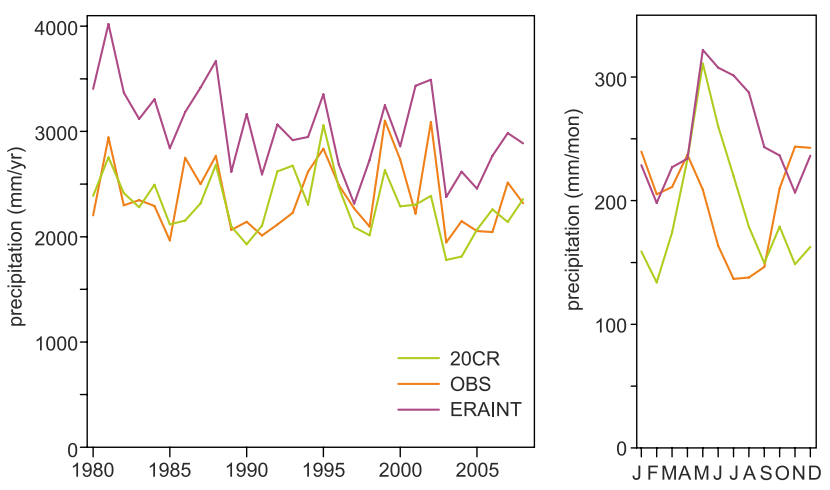

Fig. 3. Annual mean precipitation and mean seasonal cycle of precipitation over the period 1980-2008 from Great St Bernard station data, ERA-Interim, and 20CR.

\subsection{GNIP data}

For comparison we also used monthly data of $\delta^{18} \mathrm{O}$ in precipitation, temperature, and precipitation from various stations of the Global Network of Isotopes in Precipitation (GNIP) (IAEA/WMO, 2013). As the GNIP data are used in our paper in conjunction with an analysis of ERA-Interim data over the 1979-2012 period, we only selected locations with a comparable length (i.e. 1976-2009) with as few gaps as possible. The stations chosen are Krakow (Poland), Vienna (Austria), Grimsel and Bern (both Switzerland), and Ottawa (Canada).

\subsection{Correlations}

Most analyses in this paper are addressing correlations. We use the Pearson correlation coefficient. The significance of the correlations was calculated with a $t$ test accounting for autocorrelation by replacing sample size $n$ with the effective sample size $n^{*}=n(1-\rho) /(1+\rho)$, where $\rho$ is the higher of the two first-order autocorrelations of the two series compared. Unless otherwise noted, we used two-sided tests with a $95 \%$ confidence limit.

\section{Forward model}

To address the signal preservation of climate variables by the ice core we mimic the formation of an ice core from daily meteorological data (i.e. a simple forward model, see also Sime et al., 2011):

$A_{\text {fwd_daily }}=c_{1} \cdot P_{\text {daily }}$

and

$\delta^{18} \mathrm{O}_{\mathrm{fwd} \_d a i l y}=c_{2}+c_{3} \cdot T_{\text {daily }}$,

where $A$ is accumulation, $P$ is precipitation, $T$ is temperature and the subscript "fwd" stands for forward model. The model focuses only on one aspect, namely the unequal sampling of the atmosphere by the ice core and its consequences. We ignore all other effects listed in the Introduction, and the relations between precipitation and accumulation or between $\delta^{18} \mathrm{O}$ and temperature are assumed linear (see Mariani et al., 2012, for a discussion of these relations in the Grenzgletscher ice core). Unlike Wagenbach et al. (2012), for instance, we do not take snow erosion into account. More complex models could be formulated and could lead to a better agreement with the ice core data, but this is not the focus of this paper.

Based on the daily data, samples are mimicked. In the laboratory, samples of $5 \mathrm{~cm}$ ice were analysed. They can be described as

$A_{\text {fwd_sample }}=\Sigma A_{\text {fwd_daily }}$

and

$\delta^{18} \mathrm{O}_{\text {fwd_sample }}=\Sigma\left(\delta^{18} \mathrm{O}_{\text {fwd_daily }} \cdot A_{\text {fwd_daily }}\right) / A_{\text {fwd_sample }}$,

where the sum is defined such that $A_{\text {fwd_sample }}$ corresponds to a sample (mostly close to $5 \mathrm{~cm}$, but exact numbers, which may vary from sample to sample, were used). This requires knowledge of $c_{1}$, which encompasses various processes including local variability of precipitation and snow accumulation (it is estimated in the next paragraph). Since only correlations are analysed in this paper which are insensitive to the choice of $c_{2}$ and $c_{3}$, analysing $\delta^{18} \mathrm{O}_{\mathrm{fwd}}$ is equivalent to analysing precipitation-weighted temperature (PWT):

$\mathrm{PWT}=\Sigma\left(P_{\text {daily }} \cdot T_{\text {daily }}\right) / \Sigma\left(P_{\text {daily }}\right)$.

Note that in reality, the relation between $A_{\text {fwd }}$ and $P$ is nonlinear but depends on the type and amount of precipitation, and it may vary over time. Also, approximating snow accumulation on the glacier with precipitation from a distant measurement site or a reanalysis inevitably carries a large error.

We applied the model for the period autumn 1979 to spring 1994, where the ice core data show more pronounced seasonality than earlier and meteorological data are better (automated rather than manual weather station) and more abundant (ERA-Interim data). We show results based on station data in the following. To determine $c_{1}$, precise start and end dates of the given period must be defined in the real ice core. We proceeded by assuming that the last sample in the ice core represents 31 March 1994 and searched for the most likely location of 1 September 1979 in the ice core by smoothing $\delta^{18} \mathrm{O}_{\text {fwd_daily }}$ and comparing with observed $\delta^{18} \mathrm{O}$ of that autumn until a good fit was found. In this way $c_{1}$ was set to 1.20. The value can be compared to similar factors derived from glacier mass balance studies. Gabrielli et al. (2010) find a value of 1.71 for a similar setting in the eastern Alps. Kuhn (2003) finds a factor of 2.15 between accumulation and basin-averaged precipitation. However, both accumulation and precipitation may vary locally and hence a large variability of this factor is expected. 
Note that the error in $c_{1}$ is relatively small (i.e. corresponding to an error of a week or two over a period of $15 \mathrm{yr}$ ) and that the effect of mis-specifying $c_{1}$ also is small, even irrelevant for analyses in which annual layers are defined based on the coldest sample (see next section). After specifying $c_{1}, 5 \mathrm{~cm}$ samples could be defined and $A_{\text {fwd_sample }}$ and PWT could be calculated. We call the result "virtual ice core".

\section{Results}

\subsection{Sample-by-sample comparison}

A first comparison on a sample-by-sample basis showed that PWT in the virtual ice core has more high-frequency variability than $\delta^{18} \mathrm{O}$ in the real ice core. This is expected as several processes such as surface melting, percolation, and diffusion (see Johnsen et al., 2000, for a modelling approach) lead to a smoothing of the signal across the sample. We therefore smoothed the PWT in the virtual ice core with a fivepoint triangular filter (full width at half maximum equals ca. $15 \mathrm{~cm}$; see also Sime et al. (2011) for a similar approach). Results are shown in Fig. 4. The agreement between this curve and the ice core $\delta^{18} \mathrm{O}$ is now very good. The summer peaks are more smoothed out in the real ice core, most likely due to surface melting (see squared boxes), which however does not affect the winter season. In the other seasons it is often possible to identify individual wiggles in both curves (see open circles for examples). In order to quantify the agreement, quasi-annual layers need to be defined. Since the agreement is very good in the autumn to spring season, we tried a wiggle-matching approach. The wiggles representing the lowest mid-winter $\delta^{18} \mathrm{O}$ values in the real ice core were matched in the virtual ice core samples. The identified points are marked with filled dots in Fig. 4. There was ambiguity in this process in about 3-4 cases where we consulted neighbouring wiggles. We did not change decisions ex post (i.e. after the analysis of the results), so the wiggle matching was not used to further optimise correlations. However, due to the nature of the wiggle-matching approach and the smoothing, the approach is optimistic and correlations probably overestimated.

The values of $A_{\text {fwd }}$ and PWT were then calculated for the period between the points (i.e. the sum in Eq. 2 was taken over all samples between two successive cold points, mimicking the annual layer counting; see also Sime et al., 2011). The result is a series of quasi-annual values shown in Fig. 5. Pearson correlations between the virtual and the real ice core are 0.62 for accumulation and 0.80 for PWT $(n=14)$. Even though the approach is optimistic, these high correlations (the latter is significant) are surprising in view of the considerable horizontal and vertical distance of the weather station and the ice core site and in view of all other uncertainties mentioned. It shows that the ice core does indeed record meteorological information, namely the precipitationweighted average of temperature.

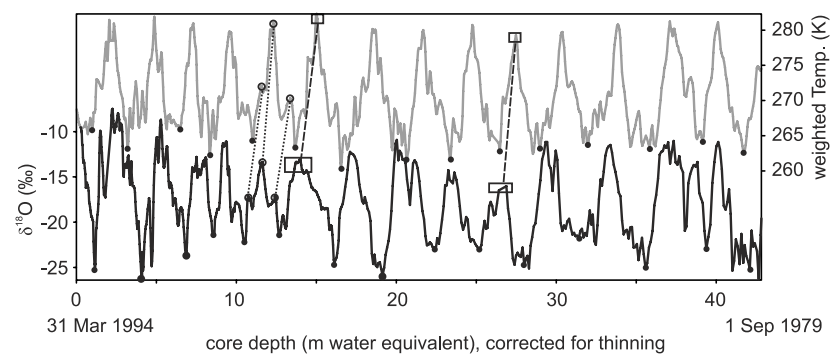

Fig. 4. Sample-by-sample depiction of the ice core $\delta^{18} \mathrm{O}$ (bottom) as well as PWT (top, using Great St Bernard station data). Black dots denote the cross dating using wiggle matching, open circles show examples of matching sub-seasonal features. Squares show examples for possible melting processes.

\subsection{Interannual resolution}

It was not possible to extend the wiggle matching to the entire record as the agreement of sub-seasonal variability deteriorated before 1980 . Therefore, we used the annual mean values as defined in Mariani et al. (2012) and compared these to two different integrations of the forward model (Fig. 6). In one version (termed "calendar year") we simply averaged the virtual ice core over the calendar year (dashed). In the other approach ("cold point year") we used the central date of the 60-day window with the minimum averaged PWT among a 180-day period during the winter half year (solid). This allows minima to occur in November or March, for instance, while mostly they occurred at some point in January. The model was fed with different meteorological data sets. For visualisation, they were scaled with a regression model calibrated against ice core $\delta^{18} \mathrm{O}$ in the $1979-1993$ period. We also analysed the temperature averaged for all precipitation days $(>0.1 \mathrm{~mm})$, termed wet-day temperature. Corresponding correlations are listed in Table 1 for the entire period as well as for the subperiod 1979-1993.

During the last period (1979-1993) all comparisons give satisfactory agreement, although not as good as for the wiggle-matching approach (note that due to the short period and high autocorrelation, no coefficient is significant). For accumulation, correlations approach 0.6 for the direct comparison between the ice core and annual mean precipitation, while they are lower for the cold point year accumulation. For $\delta^{18} \mathrm{O}$ (or PWT) there is hardly any difference between calendar year and cold point year approaches. The highest correlations are found for the comparison of $\delta^{18} \mathrm{O}$ with wetday temperature (see Mariani et al., 2012, for a more detailed discussion of correlations between Grenzgletscher accumulation and $\delta^{18} \mathrm{O}$ with meteorological fields).

For the full period, correlations are lower as was already indicated by the failure of the wiggle-matching approach. Correlations between ice core $\delta^{18} \mathrm{O}$ and annual mean temperature are 0.05 and 0.12 (depending on the meteorological data set). Higher but still insignificant correlations are found 
Table 1. Pearson correlations between accumulation and $\delta^{18} \mathrm{O}$ from the Grenzgletscher ice core with annual averages of temperature and precipitation, wet-day temperature, and accumulation and precipitation-weighted temperature (PWT) from the forward model. Different data sets are used $(\mathrm{OBS}=$ station observations, $20 \mathrm{CR}=$ Twentieth Century Reanalysis, INT = ERA-Interim). Also shown are correlations for 5 yr averages (1938-1942, 1943-1947, 1948-1952, 1953-1957, 1958-1962, 1963-1967, 1971-1975, 1976-1980, 1981-1985, 1986-1990, 1991-1993). Coefficients in italics are statistically significant $(p<0.05)$, accounting for autocorrelation.

\begin{tabular}{|c|c|c|c|c|c|c|c|c|c|c|c|c|}
\hline & \multicolumn{3}{|c|}{ Annual average ( $T$ or $P$ ) } & \multicolumn{3}{|c|}{ Wet-day temperature } & \multicolumn{3}{|c|}{$\begin{array}{l}A_{\text {fwd }} \text { or PWT, } \\
\text { cold point year }\end{array}$} & \multicolumn{3}{|c|}{$\begin{array}{l}A_{\mathrm{fwd}} \text { or PWT, } \\
\text { calendar year }\end{array}$} \\
\hline & OBS & $20 \mathrm{CR}$ & INT & OBS & $20 \mathrm{CR}$ & INT & OBS & $20 \mathrm{CR}$ & INT & OBS & $20 \mathrm{CR}$ & INT \\
\hline \multicolumn{13}{|l|}{$1979-1993$} \\
\hline Accumulation & 0.62 & 0.54 & 0.61 & & & & 0.41 & 0.41 & 0.52 & 0.62 & 0.54 & 0.61 \\
\hline$\delta^{18} \mathrm{O}$ & 0.51 & 0.43 & 0.38 & 0.71 & 0.56 & 0.52 & 0.45 & 0.53 & 0.57 & 0.52 & 0.48 & 0.39 \\
\hline \multicolumn{13}{|l|}{$1938-1993$} \\
\hline Accumulation & 0.40 & 0.40 & & & & & 0.26 & 0.31 & & 0.40 & 0.40 & \\
\hline$\delta^{18} \mathrm{O}$ & 0.05 & 0.12 & & 0.30 & 0.27 & & 0.33 & 0.41 & & 0.41 & 0.39 & \\
\hline \multicolumn{13}{|l|}{$\begin{array}{l}\text { 1938-1993 } \\
\text { (5-yr averages) }\end{array}$} \\
\hline$\delta^{18} \mathrm{O}$ & -0.06 & 0.17 & & 0.52 & 0.50 & & 0.76 & 0.79 & & 0.84 & 0.85 & \\
\hline
\end{tabular}

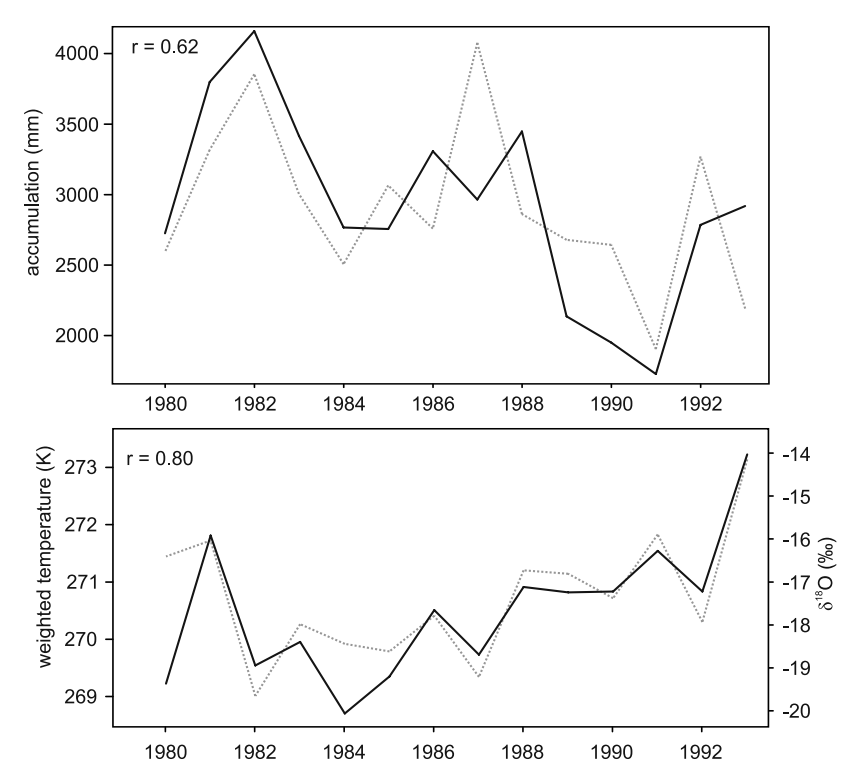

Fig. 5. Interannual variability from 1980-1993 in accumulation and $\delta^{18} \mathrm{O}$ from the ice core (black solid) and from the forward model (dashed grey line, PWT). The aggregation of samples into annual mean values was done according to the wiggles indicated in Fig. 3.

between ice core $\delta^{18} \mathrm{O}$ and wet-day temperature. In contrast, using PWT yields correlations between 0.31 and 0.41 , all of which are significant. During the dry 23 yr period 1945-1967 correlations are lower than during the wet $23 \mathrm{yr}$ period 19791993, but the difference is explainable by the deteriorating data quality and increasing dating uncertainty when going back in time.

It is interesting to compare, within the Great St Bernard station data, the annual mean temperature with PWT using

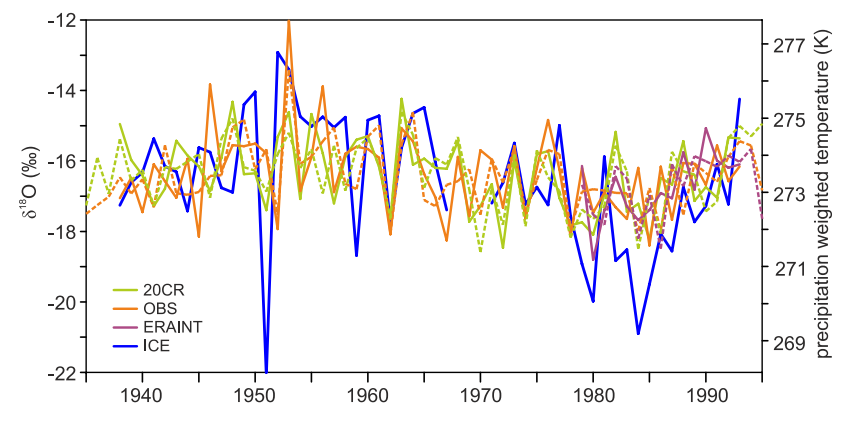

Fig. 6. Interannual variability of $\delta^{18} \mathrm{O}$ from the ice core and PWT from forward modelling (solid: cold point year, dashed: calendar year) based on different data sets.

the calendar year approach (Fig. 7). The correlation between the two series is low $(r=0.25$ for the entire 1865-2010 period, $r=0.45$ for the 1934-2010 period), which suggests that the main reason for the low correlations shown in Table 1 is the fact that the ice core does not record temperatures during dry conditions (note that the definition of the year is the same). PWT has a higher variance than annual mean temperature.

In the real ice core, additional effects such as dating uncertainties could further contribute to low correlations. The precision of dating was estimated to be $\pm 1 \mathrm{yr}$ for the period 1970-1994 and \pm 3 yr for 1937-1969 (Eichler et al., 2000). With respect to observations, the low value in 1951 appears as an outlier. However, Eichler et al. (2000) attributed this value to cold, snowy conditions in January and February of that year causing a large number of avalanches (Pfister, 1999). Also, 20CR shows a slightly lower value in that year. It does appear, however, that negative extremes deviate more strongly from the observations than positive ones, suggesting 


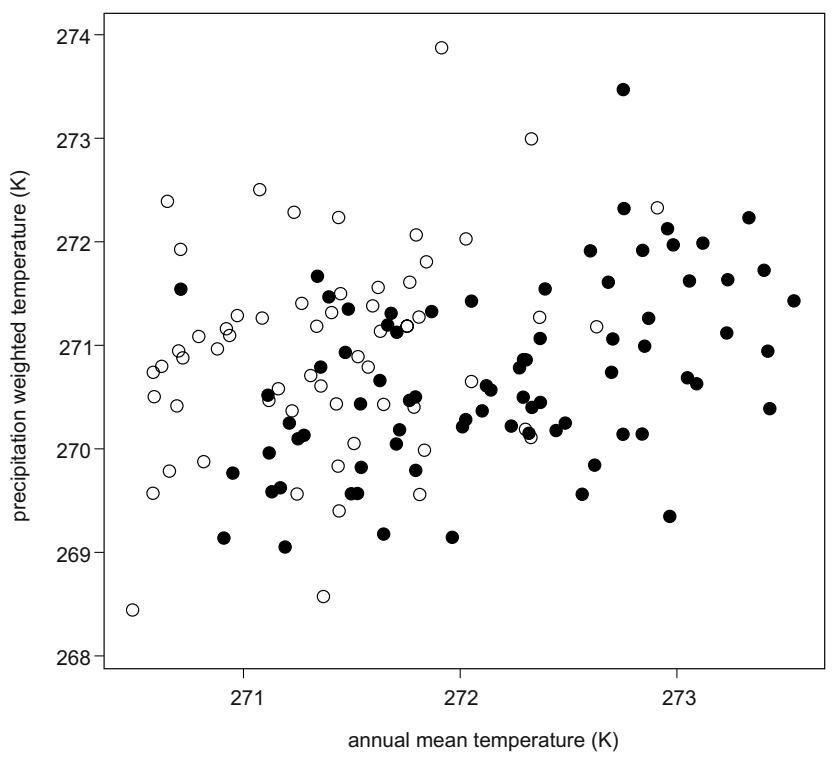

Fig. 7. Comparison of annual mean temperature versus PWT based on daily data from the Great St Bernard in the periods 1864-1924 (open circles) and 1934-2010 (filled circles).

that the extreme conditions at high-Alpine sites are not well represented in some of the data sets.

This analysis shows that the further back in time one goes, the more uncertain the information from ice cores is. It also shows, however, that there still is a significant correlation between ice core and temperature, but not with annual mean temperature. There is almost no difference between the calendar year and the cold point year. While the former is simpler, the latter is more plausible given the sampling and arguably less affected by non-stationarity problems.

All attempts to develop the forward model further, i.e. to account for variations in lapse rates between the Great $\mathrm{St}$ Bernard and Grenzgletscher (or to interpolate the reanalyses to a fixed altitude), or to account for the main wind direction by sampling reanalysis temperatures $3 \mathrm{~h}$ upwind did not improve the results.

\subsection{Multiannual variability}

Interannual variability might still be affected by postdepositional processes or dating errors. We therefore also tested correlations based on 5 yr averages (1938-1967, 1970-1993; the last period was only $3 \mathrm{yr}$ ). The correlations improved considerably for the forward model, to around 0.8 (Table 1), while they remained low for the annual mean temperature. Correlations for wet-day temperature are inbetween.

This analysis again shows that a temperature signal is contained in the ice core. The definition of the annual average does not matter much, as the corresponding error in one year is largely compensated by the error of the next year.
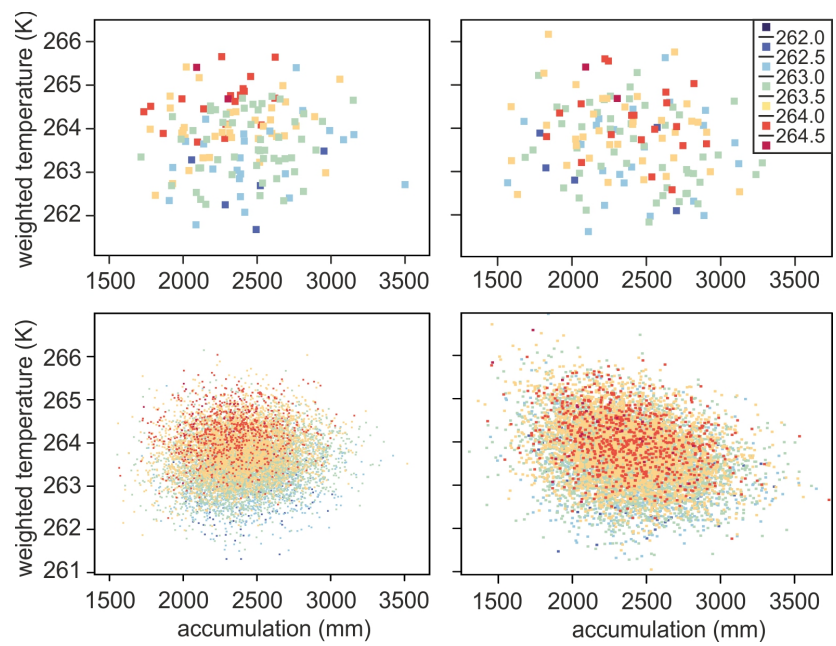

Fig. 8. Annual mean temperature (colour) as a function of accumulation and PWT in the virtual ice cores using the calendar (left) or cold point (right) year. Top: virtual ice core from 20CR. Bottom: virtual ice core from the Monte Carlo resampling of 20CR, 18712008 (10000 realisations).

\subsection{Analyses of PWT in reanalyses}

Reanalyses are available for $140 \mathrm{yr}$. The virtual ice core can thus be extended far beyond the real ice core. This allows studying the relation between annual mean temperature and PWT within the virtual ice core (Fig. 8). We used both the calendar year and the cold point year. For the former, $A_{\mathrm{fwd}}$ and annual mean precipitation have a correlation of 1 by definition. The Pearson correlation between PWT and annual mean temperature is 0.6. Note that the deviation from a correlation of 1 is only due to the difference between the accumulation-weighted average and the true average. Other potential errors such as the definition of the year or uncertainties in meteorological data or ice core data are excluded by construction. For the cold point year the correlation between PWT and annual mean temperature drops further to 0.34 . Note that this experiment still assumes perfect data (no uncertainties in meteorological data or ice core data), thus demonstrating that sampling alone is sufficient to account for the low correlations at interannual time scales. In other words, a given combination of $\delta^{18} \mathrm{O}$ and accumulation can be achieved in many different ways so that conclusions about mean temperature are difficult.

We extended the approach to a global perspective by calculating, in ERA-Interim reanalysis data, PWT for the calendar year approach and comparing it with annual mean temperature over the entire period (1979-2012, thus $n=34$ ). Results (Fig. 9) show that many regions, including polar areas and midlatitude continental areas, exhibit rather low, sometimes insignificant correlations (only correlations with $p$ values $<0.1$ are shown, accounting for autocorrelation). These results are consistent with other studies (see also 


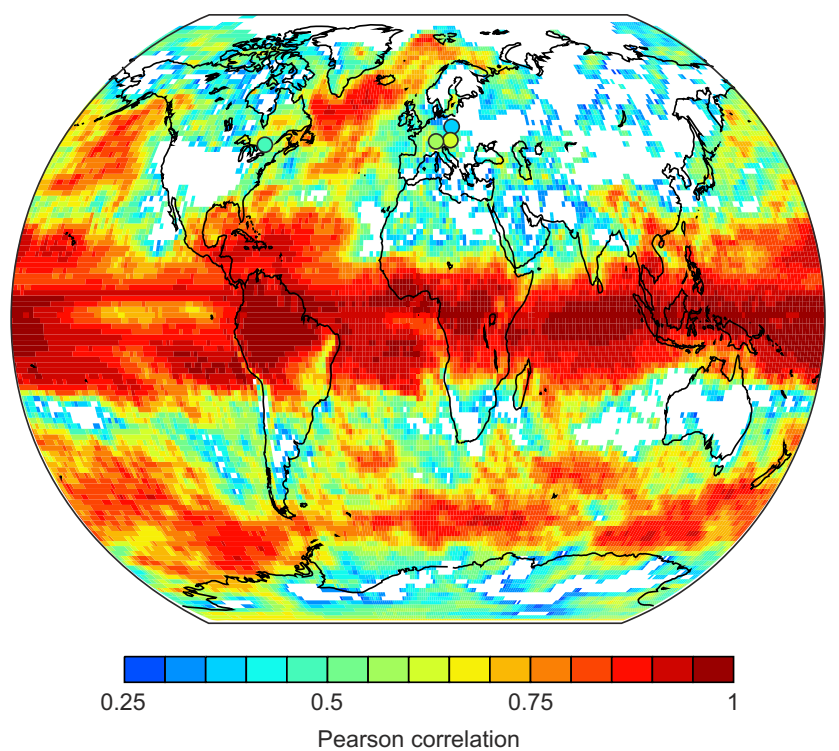

Fig. 9. Map of the Pearson correlation coefficient between annual mean temperature and PWT (calendar year) over the period 19792012 calculated from ERA-Interim data. Circles denote correlations between annual mean temperature and annual $\delta^{18} \mathrm{O}$ at four GNIP stations (calculated as precipitation-weighted sum of monthly $\delta^{18} \mathrm{O}$ values). Only correlations that are significant $(p<0.1)$, accounting for autocorrelation, are shown.

Sturm et al., 2010; Sime et al., 2011; Persson et al., 2011). We also calculated corresponding correlations from GNIP data $\left(\delta^{18} \mathrm{O}\right.$, precipitation, temperature) for five stations with good temporal coverage (at least 30 complete years between 1976 and 2009). From the monthly samples, we calculated a precipitation-weighted, annual average of $\delta^{18} \mathrm{O}$ and compared it with annual mean temperature. Gaps of one month (of which there were only few) were interpolated; if gaps longer than one month occurred, the corresponding year was rejected. Correlations for these five stations (circles in Fig. 9) fit very well with the ERA-Interim analysis (values for Bern and Grimsel are almost identical and only one circle is shown).

\subsection{Analyses of PWT in weather generators}

In order to improve the data coverage and better populate Fig. 8, weather generators could possibly be used. We simulated two $10000 \mathrm{yr}$ records using different approaches. First, we used the LARS WG stochastic weather generator (Semenov et al., 1998) to simulate Great St Bernard station observations. For calibrating the weather generator, we used observed daily maximum and minimum temperature, precipitation, and global radiation from the years 1981 to 2012 . The weather generator reproduced most of the statistical features of the data, but underestimated precipitation variability in spring. Second, we sampled 20CR by stacking sequences of length $l=15$ days (representing an upper limit of the

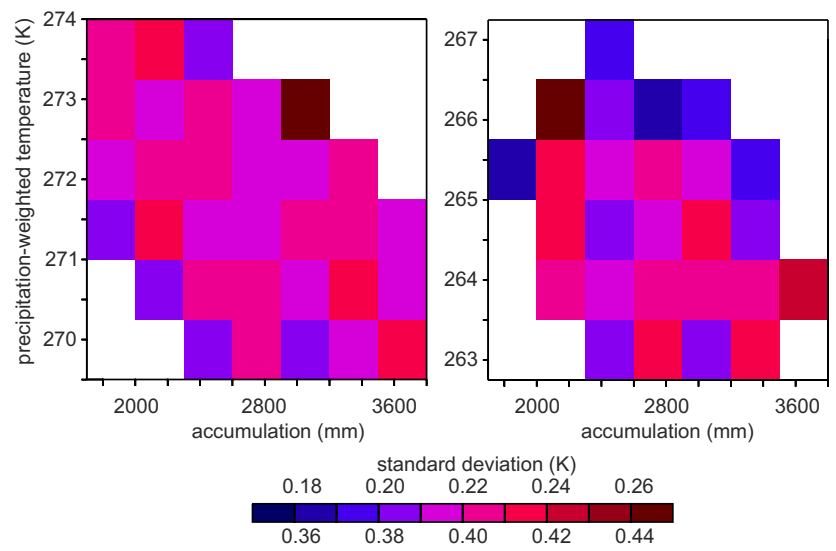

Fig. 10. Standard deviation of annual mean temperature at Great St Bernard (left, upper scale) and in $20 \mathrm{CR}$ at $600 \mathrm{hPa}$ (right, lower scale) as a function of accumulation and PWT using data from two weather generators. At least 40 points were required to calculate a standard deviation.

long-range memory of atmospheric circulation), randomly sampled from the 1871-2008 record, but the calendar day was allowed to vary somewhat (i.e. we sampled the corresponding calendar day plus a Gaussian random offset with $\mu=0$ days, $\sigma=5$ days; the latter corresponds to a climatological temperature change of at most $1{ }^{\circ} \mathrm{C}$ in spring and fall). Note that other weather generators could be used to generate more realistic weather and might lead to better results, but the chosen weather generators serve the purpose of illustrating the uncertainties in signal preservation by the ice core more fully than in Sect. 4.4.

From the artificial meteorological records we proceeded as before (daily mean temperature in generator 1 was defined as the average of maximum and minimum temperature), using both the calendar and cold point years. The results (shown in Fig. 8 bottom, for generator 2) confirm those found in Sect. 4.4 from 20CR, with correlations around 0.27 for the calendar year approach and 0.12 for the cold point year. Binning the generated records according to $A_{\mathrm{fwd}}$ and PWT allows analysing the standard deviation of annual mean temperature for a given combination of $A_{\mathrm{fwd}}$ and PWT (Fig. 10 for the cold point year, both generators). Results reveal slightly smaller standard deviations for low $A_{\text {fwd }} /$ low PWT or high $A_{\text {fwd }} /$ high PWT combinations (off the diagonal) as compared to more common combinations, confirming that there are many different ways to arrive at an "average" combination of $A_{\mathrm{fwd}}$ and PWT but arguably less different ways for obtaining the more unusual "cold/dry" and "warm/wet" combinations.

\section{Conclusions}

The goal of this paper was to formulate a simple forward model that replicates the preservation of the atmospheric 
signals by the ice core (precipitation event by precipitation event or sample by sample) and the determination of annual layers. For the specific case of Grenzgletscher, the model shows that the ice core does contain temperature information even though there is only a low correlation between annual mean temperature and ice core $\delta^{18} \mathrm{O}$. Using reanalysis data and Monte Carlo techniques we show that low correlations between annual mean temperature and precipitationweighted temperature are expected, as a given combination of $\delta^{18} \mathrm{O}$ and accumulation can be achieved in many different ways.

The $\delta^{18} \mathrm{O}$ average of an ice core layer represents a precipitation-weighted temperature rather than annual mean temperature. Therefore, the best way to make use of layeraveraged $\delta^{18} \mathrm{O}$ in an ice core is to reconstruct precipitationweighted temperature rather than annual mean temperature. Precipitation-weighted temperature is reproducible in meteorological data and reanalyses. Hence, it could possibly be assimilated into conventional climate models (e.g. Bhend et al., 2012) as an alternative to assimilating $\delta^{18} \mathrm{O}$ directly into an isotope-enabled modelling system.

Acknowledgements. This work was supported through the Swiss National Science Foundation (NCCR Climate, Project PALVAREXIII and Project FUPSOL). 20CR data were provided by courtesy of the NOAA/OAR/ESRL PSD, Boulder, Colorado, USA (http://www.esrl.noaa.gov/psd/). Support for the Twentieth Century Reanalysis Project dataset is provided by the US Department of Energy, Office of Science Innovative and Novel Computational Impact on Theory and Experiment (DOE INCITE) program, and Office of Biological and Environmental Research (BER), and by the National Oceanic and Atmospheric Administration Climate Program Office.

Edited by: C. Barbante

\section{References}

Bhend, J., Franke, J., Folini, D., Wild, M., and Brönnimann, S.: An ensemble-based approach to climate reconstructions, Clim. Past, 8, 963-976, doi:10.5194/cp-8-963-2012, 2012.

Casado, M., Ortega, P., Masson-Delmotte, V., Risi, C., Swingedouw, D., Daux, V., Genty, D., Maignan, F., Solomina, O., Vinther, B., Viovy, N., and Yiou, P.: Impact of precipitation intermittency on NAO-temperature signals in proxy records, Clim. Past, 9, 871-886, doi:10.5194/cp-9-871-2013, 2013.

Compo, G. P., Whitaker, J. S., Sardeshmukh, P. D., Matsui, N., Allan, R. J., Yin, X., Gleason, B. E., Vose, R. S., Rutledge, G., Bessemoulin, P., Brönnimann, S., Brunet, M., Crouthamel, R. I., Grant, A. N., Groisman, P. Y., Jones, P. D., Kruk, M., Kruger, A. C., Marshall, G. J., Maugeri, M., Mok, H. Y., Nordli, Ø., Ross, T. F., Trigo, R. M., Wang, X. L., Woodruff, S. D., and Worley, S. J.: The Twentieth Century Reanalysis Project, Q. J. Roy. Meteorol. Soc., 137, 1-28, 2011.

Dee, D. P., Uppala, S. M., Simmons, A. J., Berrisford, P., Poli, P., Kobayashi, S., Andrae, U., Balmaseda, M. A., Balsamo, G.,
Bauer, P., Bechtold, P., Beljaars, A. C. M., van de Berg, L., Bidlot, J., Bormann, N., Delsol, C., Dragani, R., Fuentes, M., Geer, A. J., Haimberger, L., Healy, S. B., Hersbach, H., Hólm, E. V., Isaksen, L., Kållberg, P., Köhler, M., Matricardi, M., McNally, A. P., Monge-Sanz, B. M., Morcrette, J.-J., Park, B.-K., Peubey, C., de Rosnay, P., Tavolato, C., Thépaut, J.-N., and Vitart F.: The ERA-Interim reanalysis: configuration and performance of the data assimilation system, Q. J. Roy. Meteorol. Soc., 137, 553597, 2011.

Eichler, A., Schwikowski, M., Gäggeler, H. W., Furrer, V., Synal, H.-A., Beer, J., Saurer, M., and Funk, M.: Glaciochemical dating of an ice core from the upper Grenzgletscher (4200 m a.s.1.), J. Glaciol., 46, 507-515, 2000.

Eichler, A., Schwikowski, M., and Gäggeler, H. W.: Meltwaterinduced relocation of chemical species in Alpine firn, Tellus B, 53, 192-203, 2001.

Gabrielli, P., Carturan, L., Gabrieli, J., Dinale, R., Krainer, K., Hausmann, H., Davis, M., Zagarodnov, V., Seppi, R., Barbante, C., Dalla Fontana, G., and Thompson, L. G.: Atmospheric warming threatens the untapped glacial archive of Mt. Ortles, South Tyrol, J. Glaciol., 56, 843-853, 2010.

IAEA/WMO: Global Network of Isotopes in Precipitation, The GNIP Database, available at: http://www.iaea.org/water (last access: 6 June 2013), 2013.

Johnsen, S., Clausen, H., Cuffey, K., Hoffmann, G., Schwander, J., and Creyts, T.: Diffusion of stable isotopes in polar firn and ice: the isotope effect in firn diffusion, in Physics of Ice Core Records, edited by: Hondoh, T., 121-140, Hokkaido University Press, Sapporo, 2000.

Kuhn, M.: Redistribution of snow and glacier mass balance from a hydrometeorological model, J. Hydrol., 282, 95-103, 2003.

Läpple, T., Werner, M., and Lohmann, G.: Synchronicity of Antarctic temperatures and local solar insolation on orbital timescales, Nature, 471, 91-94, 2011.

Lee, J. E. and Fung, I.: Amount effect of water isotopes and quantitative analysis of postcondensation processes, Hydrol. Process., 22, 1-8, doi:10.1002/hyp.6637, 2008.

Mariani, I., Eichler, A., Brönnimann, S., Auchmann, R., Jenk, T. M., Leuenberger, M. C., and Schwikowski, M.: Temperature and precipitation signal in two Alpine ice cores over the period 19612001, Clim. Past Discuss., 8, 5867-5891, doi:10.5194/cpd-85867-2012, 2012.

Nye, J. F.: Correction factor for accumulation measured by the thickness of the annual layers in an ice sheet, J. Glaciol., 4, 785788, 1963.

Persson, A., Langen, P. L., Ditlevsen, P., and Vinther, B. M.: The influence of precipitation weighting on interannual variability of stable water isotopes in Greenland, J. Geophys. Res., 116, D20120, doi:10.1029/2010JD015517, 2011.

Pfahl S. and Wernli, H.: Air parcel trajectory analysis of stable isotopes in water vapor in the eastern Mediterranean, J. Geophys. Res., 113, D20104, doi:10.1029/2008JD009839, 2008.

Pfister, C.: Wetternachhersage - 500 Jahre Klimavariationen und Naturkatastrophen, Haupt, Bern, 1999.

Semenov, M. A., Brooks, R. J., Barrow, E. M., and Richardson, C. W.: Comparison of the WGEN and LARS-WG stochastic weather generators for diverse climates, Clim. Res., 10, 95-107, 1998. 
Sime, L. C., Marshall, G. J., Mulvaney, R., and Thomas, E. R.: Interpreting Temperature Information from Ice Cores Along the Antarctic Peninsula: ERA40 Analysis, Geophys. Res. Lett., 36, L18801, doi:10.1029/2009GL038982, 2009.

Sime, L. C., Lang, N., Thomas, E. R., Benton, A. K., and Mulvaney, R.: On High-resolution Sampling of Short Ice Cores: Dating and Temperature Information Recovery from Antarctic Peninsula Virtual Cores, J. Geophys. Res., 116, D20117, doi:10.1029/2011JD015894, 2011.

Steen-Larsen, H. C., Winkler, R., Prie, F., Landais, A., MassonDelmotte, V., Risi, C., Berkelhammer, M. B., Noone, D. C., O'Neill, M., Guillevic, M., Hirabayashi, M., Schneider, D. P., and Stenni, B.: Triple water vapor isotopic (H218O, HD16O, $\mathrm{H} 217 \mathrm{O})$ measurements above the Greenland Ice Sheet and importance for understanding the atmospheric hydrological cycle in the Arctic, EOS T. Am. Geophys. Un., Fall Meet. Suppl, Abstract A53V-03, 2012.
Stucki, P., Rickli, R., Brönnimann, S., Martius, O., Wanner, H., Grebner, D., and Luterbacher J.: Weather patterns and hydroclimatological precursors of extreme floods in Switzerland since 1868, Meteorol. Z., 21, 531-550, 2012.

Sturm, C., Zhang, Q., and Noone, D.: An introduction to stable water isotopes in climate models: benefits of forward proxy modelling for paleoclimatology, Clim. Past, 6, 115-129, doi:10.5194/cp-6-115-2010, 2010.

Wagenbach, D., Bohleber, P., and Preunkert, S.: Cold, Alpine ice bodies revisited: what may we learn from their impurity and isotope content?, Geogr. Ann. A, 94, 245-263, doi:10.1111/j.14680459.2012.00461.x, 2012.

Werner, M., Mikolajewicz, U., Heimann, M., and Hoffmann G.: Borehole versus isotope temperatures on Greenland: seasonality does matter, Geophys. Res. Lett., 27, 723-726, 2000. 